\title{
BMJ Open Volunteering and overseas placements in the NHS: a survey of current activity
}

\author{
John Chatwin, Louise Ackers
}

To cite: Chatwin J, Ackers L. Volunteering and overseas placements in the NHS: a survey of current activity. BMJ Open 2016;6:e012160. doi:10.1136/bmjopen-2016012160

- Prepublication history and additional material is available. To view please visit the journal (http://dx.doi.org/ 10.1136/bmjopen-2016012160).

Received 4 April 2016 Accepted 29 July 2016

\section{ABSTRACT}

Objective: The study aimed to establish current levels of overseas volunteering and placement activity across all staff grades within the National Health Service (NHS) in the North West of England.

Design: Cross-sectional survey. Instrument: Descriptive statistics.

Setting: 4 main regional hospitals in the North West of England, and additional NHS staff training events.

Participants: Convenience sample of NHS staff $(n=911)$.

Results: 911 NHS staff took part in the survey. The medical and dental staff group returned the highest number of responses (32.1\%). $42 \%$ of staff reported some form of overseas volunteering or placement experience. Most staff took an international placement as students (33.6\% men; $40.6 \%$ women). Mediumterm placements were undertaken by $46.7 \%$ of men, and $52.5 \%$ of women. Settlement stays (ie, over 1 year) were reported by $7.6 \%$ men, and $8.3 \%$ women). The majority of respondents engaged in international placement were from the age groups incorporating 'below 25' to ' $41-50$ ' (74\%). Multiple placement experiences were uncommon: $2.5 \%$ of respondents reported three periods of overseas activity, and $1.5 \%$ reported four. All those with multiple placement experience came from the staff groups incorporating midwife/nurse/health visitor, and medical and dental.

Conclusions: This survey captured a snapshot of current levels of volunteering and overseas placement activity across NHS staff grades in the North West. Owing to relatively homogenous organisational structures, findings are likely to broadly represent the position across the organisation as a whole. Although some degree of overseas placement activity is undertaken by a relatively high proportion of NHS staff, such activity is currently heavily skewed towards higher clinical staff grades. Significant numbers of allied health professionals and equivalent non-clinical cadres also report overseas experience, and we anticipate that the numbers will continue to rise if current policy initiatives gain momentum.

\section{INTRODUCTION}

Undertaking a period of voluntary work or a placement overseas has long been a feature of medical training in the UK, and the

\section{Strengths and limitations of the study}

- This is the first large-scale survey focusing specifically on National Health Service (NHS) staff volunteering and overseas experience.

- The survey includes a representational sample across all staff grades, and provides important baseline data which underpins current policy initiatives.

- The cross-sectional nature of our study prohibits firm conclusions about causality in relation to volunteering and placement provision.

- We used a convenience sample, which may not reflect the finer details of relative staffing levels across the entire NHS.

- We did not gather data relating to the specific barriers and enablers to volunteering that staff in the different cadres encountered.

option to participate in such activity is built in to a wide variety of clinical training programmes. ${ }^{1}$ Until recently, providing such opportunities for the myriad of other grades and roles within the National Health Service (NHS) (particularly non-clinical ones), has not been a priority and employment structures within the organisation have remained relatively inflexible in this respect. ${ }^{2}$ However, the potential value that even short periods within foreign healthcare and cultural contexts can bring both to individual employees, and the wider NHS is now being more broadly recognised. ${ }^{3}$ There are currently a number of high profile healthcare training initiatives in the UK aimed at increasing the availability of, and access to, overseas volunteering and placement opportunities for staff at all levels.

This move towards a greater integration of overseas experience is seen as an opportunity to capitalise on a rich potential learning resource that is not purely limited to clinical skills. ${ }^{4}$ Traditionally, volunteering has claimed to fulfil mainly altruistic aspects of social responsibility, but its mutual learning and knowledge mobilisation benefits are now also being recognised. ${ }^{3}$ 5-7 The potential benefits to the NHS claimed for volunteering 
and placement activities abroad include the entrenchment of the organisation's core values-the so-called '6 Cs': care, compassion, competence, communication, courage and commitment. ${ }^{8}$ However, there may be other, more tangentially beneficial, effects that result from participation. ${ }^{9}$ These include development of 'soft skills' such as communication awareness, leadership and team working which are so often reported by returning volunteers. ${ }^{10-12}$

Despite evidence for the educational benefits of international placements, and an extensive experiential literature relating to the personal and psychosocial impact that such experience can have ${ }^{13-15}$ there is little concrete data relating to the more pragmatic issues of cost and systemic (ie, NHS) access. The mechanisms by which experiences actually lead to 'gain' or 'loss', at whatever level, are also poorly understood. There have, for example, been calls for medical students to receive greater preparation for the clinical and ethical challenges of working in low-income countries, ${ }^{16}$ and there are arguments over the relative benefits of short and long stays. Similarly, quantifying the educational impact of international elective placements on non-medical healthcare professional students is now a priority as they become more common in UK undergraduate courses.

At a broader level, there are debates over the underlying nature of the international aid systems within which so much overseas professional volunteering is nested. The UK is becoming increasingly aid-sceptical, ${ }^{17}$ and there is pessimism over the success of development agendas. ${ }^{18} 19$ Indeed, there may be fundamental systemic reasons why the basic professional volunteering models which have become fairly ubiquitous can no longer be defended in altruistic terms. According to some commentators they could even be seen simply as another facet of the dysfunctional international aid system which continues to be 'an unmitigated political, economic and humanitarian disaster for most parts of the developing world'. ${ }^{20}$

Regardless of the underlying ethical arguments which $\operatorname{dog}$ this field, the NHS continues to move towards a placement 'access to all' culture-at least at a very broad policy level. However, at present there is virtually no reliable baseline information on the actual nature and level of activity across the organisation. This is a significant gap in our knowledge because without such data, any reported increase in the availability and uptake of future opportunities will be difficult to measure. So it is to begin to address this relatively straightforward question that the survey we describe in this article was undertaken.

\section{Context of the survey: the MOVE project}

The survey was a discrete component of the mixed methods study Measuring the Outcomes of Volunteering for Education (MOVE) ${ }^{21}$ which aimed to explore the issues and context around international placements skills gain, and describe core personal and professional skills outcomes that are directly relevant to the NHS. MOVE consisted of two distinct, yet interwoven thematic strands that broadly encompassed both qualitative and quantitative approaches. On the quantitative side the aim was to produce a psychometric tool that could be used by placement providers to match staff with specific types of overseas activity. A parallel qualitative theme was concerned with exploring the more difficult to quantify elements of motivation and experiential understanding that volunteers report. In order to underpin both of these themes, we undertook the current survey to obtain an indication of current baseline levels of volunteering and placement activity across all staff grades in the NHS.

\section{METHODS}

\section{Participants}

This was a cross-sectional staff survey, performed between January and August 2015 at four large NHS sites in the North West. These were two main regional teaching hospitals: Salford Royal Infirmary and the University Hospital of South Manchester NHS Foundation Trust (Wythenshawe Hospital). We also recruited at Liverpool Women's Hospital, which is a major obstetrics, gynaecology and neonatology research hospital; and Liverpool Community Health Trust, which is a regional hub for the administration of over 3000 NHS staff in the North West. We undertook supplementary recruitment at the 2015 Royal College of Nursing Research Conference, and a large Community-Based Medical Education training event held in April 2015. We used an offline questionnaire based survey constructed using eForms software (see the eforms webpages at. http://blogs.mcrmed.manchester.ac.uk/eforms/ (accessed 23 March 2016)). The survey was designed to be completed electronically on a one-to-one basis using an iPad. Researchers worked in teams of two or three in public access areas at each of the study sites where a wide variety of staff grades would be likely to present. Such areas included canteens, main entrances and thoroughfares. Potential respondents were identified as those displaying NHS identification. The survey took around $2 \mathrm{~min}$ to complete and was anonymous. Respondents were automatically assigned a code number by the eForms system and responses were then stored offline in the iPad. Data were downloaded to a central online database at the end of each fieldwork session.

\section{Survey design}

The survey consisted of seven sections: (1) Staff group. This was based on the eight standard employment categories currently used by human resource departments across the NHS: (a) allied healthcare professionals (HCPs) (b) healthcare scientists (c) medical and dental (d) NHS infrastructure (e) scientific and technical (f) ambulance staff $(\mathrm{g})$ nursing midwifery and health visitors (h) clinical support staff; (2) Current career stage. (a) preuniversity (b) student (c) early-career (d) mid- 
career (e) experienced/senior (f) postretirement; (3) Age (4) Gender; (5) Nationality. (6) Respondents who indicated that they had time periods of stay in another country, either as an employee or volunteer proceeded to a final section which focused on specific details for each period abroad and included questions on: (a) the economic status of country (high, middle or low income); (b) career stage when abroad: preuniversity; student; early-career; mid-career; experienced/senior; postretirement. Basic qualitative information relating to length of stay and type of placement were also collected where relevant. The layout of the survey can be seen in the online supplementary file.

\section{Statistical analysis}

Data analysis was performed using the Statistical Package for the Social Sciences (SPSS Statistics for Windows, V.22.0. Armonk, New York: IBM Corp). Descriptive statistics were used to provide a summary of the key features of the data.

\section{RESULTS}

\section{Overall makeup of the sample}

A total of 911 NHS staff took part in the survey. The medical and dental staff group returned the highest number of responses (292), which represented $32.1 \%$ of the overall survey total. The group encompassing nurses, midwives and health visitors contained 286 respondents, or $31.4 \%$ of the survey total; allied HCPs made up the third highest group with 115 respondents and $12.6 \%$ of the survey total. The remaining staff cadres included; clinical support staff (91 respondents/10\% of survey); NHS infrastructure (66 respondents/7.2\% of survey); ambulance staff (21 respondents/2.3\% of survey); health scientists ( 40 respondents $/ 4.4 \%$ of survey).

The sample was comprised of the following nationalities: British 734 respondents (81\% of total sample); European 107 respondents (12\%); non-European Union (EU) national (developing country) 59 respondents (7\%); non-EU national (developed country) 10 respondents $(1 \%)$; Other 1 respondent $(0.1 \%)$.

Overall, 389 (42\% of total) members of staff reported at least one overseas placement experience. Of these, 77 $(20 \%)$ had worked in a high-income location; $86(22 \%)$ in a middle-income; $226(58 \%)$ in a low-income location. In terms of the relative percentages from each staff group, the three highest responding groups were medical and dental (140 respondents, 36\%); nursing/ midwifery and health visitor (82 respondents, 21\%); allied HCPs (71 respondents, $18 \%$ of total). Fifty-eight clinical support staff (15\%), 15 NHS infrastructure (4\%); 15 health scientists (4\%); and 8 ambulance staff (2\%) made up the remaining volunteer totals.

The survey included 392 men and 519 women. The gender balance in relation to those who had volunteered or had taken an international placement was 172 men and 217 women. Table 1 shows the gender balance among volunteers across the various staff grades. Medical/dental men represented the largest group (82 respondents, $48 \%$ ), followed by allied HCPs (43 respondents, 25\%) and support to clinical staff (20 respondents, $12 \%)$. There were 20 clinical support staff $(12 \%$ of male volunteers); 10 health scientists $(6 \%$ of male volunteers); 7 ambulance staff (4\% of male volunteers); 8 nurse/midwife/health visitors $(5 \%$ of male volunteers). The smallest male group were NHS infrastructure, with 2 volunteers $(1 \%)$. For women, it was the group representing nurses, midwives and health visitors that reported most experience of international placements with 74 respondents (34\%) followed by medical/ dental with 58 respondents (27\%), and clinical support staff 38 respondents (18\%). The remaining women were split between allied HCPs: 28 respondents (13\%); NHS infrastructure: 13 respondents $(6 \%)$ and health scientists: 5 respondents $(2 \%)$. Female ambulance staff represented the smallest group with 1 respondent or $0.5 \%$ of the total female volunteers.

\section{Career stage}

Table 2 illustrates the gender split within the survey cross tabulated by career stage. It can be seen that most men took an international placement while they were students $(56,33.6 \%)$ followed by early career (46, $26.7 \%)$ and mid-career $(38,22.1 \%)$. The remaining $19 \%$ were split between preuniversity $(11,6.4 \%)$; experienced $(18,10.5 \%)$, and postretirement $(3,1.7 \%)$. Women also tended to favour international placement experience while they were students $(88,40.6 \%)$, with $68(31.3 \%)$ going during their early career, and 32 $(14.3 \%)$ at mid-career.

\section{Length of stay}

Table 3 illustrates the length of time spent abroad by respondents. Length of stay was defined as short term (under a week); medium term (over 2 weeks); long term (over 3 months) and settlement (over 1 year). Males, on average, favoured medium term placements $(80,46.7 \%)$ followed by long-term stays $(41,23.8 \%)$. About 31 (18\%) of males reported a short-term stay. A total of 114 of females $(52.5 \%)$ took a medium term placement, with $42(19.4 \%)$ long-term and $42(15.2 \%)$ short term. Respondents who chose to make an extended stay (ie, settlement) were similarly matched in terms of gender: $13(7.6 \%)$ were men, and $18(8.3 \%)$ women.

Table 4 shows the age group reported by respondents, cross tabulated against length of stay. The majority of respondents engaged in international placement were from the age groups incorporating 'below 25' to ' $41-50$ ' (288 of a total of 389 respondents, $74 \%$ ), with $94(50 \%)$ engaging in medium term placements. Overall, medium term placements were the most accessed, with a total of $194(49.9 \%)$ of respondents across all age groups. Settlement stays represented the smallest discrete group, with 31 respondents (7.9\%). 17 respondents (4.3\%) defined their activity as 'other'. 
Table 1 Relative percentages of staff groups by gender volunteering in another country

\begin{tabular}{|c|c|c|c|c|c|c|c|c|}
\hline \multirow[b]{2}{*}{ Gender } & \multicolumn{7}{|c|}{ Professional group } & \multirow[b]{2}{*}{ Total } \\
\hline & $\begin{array}{l}\text { Nurse/midwife } \\
\text { health visitor }\end{array}$ & $\begin{array}{l}\text { Allied } \\
\text { HCPs }\end{array}$ & $\begin{array}{l}\text { Medical } \\
\text { and dental }\end{array}$ & $\begin{array}{l}\text { Support to } \\
\text { clinical staff }\end{array}$ & $\begin{array}{l}\text { NHS } \\
\text { infrastructure }\end{array}$ & $\begin{array}{l}\text { Amb } \\
\text { staff }\end{array}$ & $\begin{array}{l}\text { Health } \\
\text { scientist }\end{array}$ & \\
\hline \multicolumn{9}{|l|}{ Male } \\
\hline Count & 8 & 43 & 82 & 20 & 2 & 7 & 10 & 172 \\
\hline $\begin{array}{l}\text { Percentage } \\
\text { within gender }\end{array}$ & 4.7 & 25.0 & 47.7 & 11.6 & 1.2 & 4.1 & 5.8 & 100.0 \\
\hline \multicolumn{9}{|l|}{ Female } \\
\hline Count & 74 & 28 & 58 & 38 & 13 & 1 & 5 & 217 \\
\hline $\begin{array}{l}\text { Percentage } \\
\text { within gender }\end{array}$ & 34.1 & 12.9 & 26.7 & 17.5 & 6.0 & 0.5 & 2.3 & 100.0 \\
\hline
\end{tabular}

\section{Multiple placement experience}

It was relatively unusual for employees to report such multiple placement experiences. For example, 10 $(2.5 \%)$ respondents reported three time periods of overseas activity, and only $6(1.5 \%)$ of those with overseas experience reported four. All those with multiple placement experience came from the three staff groups incorporating midwife/nurse/health visitor (3 with 3 placements, and 3 with 4 placements); allied HCPs (2 with 3 placements and 1 with 4 placements), and medical and dental (5 with 3 placements and 2 with 4 placements), respectively.

\section{DISCUSSION}

This was the first large-scale survey of overseas volunteering and placement activity within the NHS. The characteristics analysed were sociodemographic (staff group; career stage; age; nationality; gender), and career related (whether or not a person had volunteered, or conducted a placement abroad; at what point in their career they were when they undertook the activity). Although we used a convenience sample we focused on recruitment in locations where there were likely to be a very broad mix of staff grades. This resulted in a sample that in many ways reflects the actual staffing profile by cadre across the NHS in the North West (NHSNW) ${ }^{22}$ For example, the largest percentage of the
NHS workforce in the NHSNW was nurses and midwives at $30 \%$; and $31 \%$ of the respondents in our survey were from this staff group. Similarly, at the other end of the scale, healthcare scientists represent around 3\% of the actual workforce, and we were able to include just over $4 \%$ in the survey. Where our sample may be slightly skewed is in the number of medical and dental respondents we interviewed. Actual employment data indicate that this group makes up $9.5 \%$ of the workforce in the North West, whereas at $32.1 \%$ of our sample, there is some over-representation. In terms of the relative proportions of staff activity that we are primarily concerned with, however, this is not significant.

In line with much of the literature on volunteering and placements within health and medical contexts the survey indicates that the staff group with the highest proportion of overseas activity are medical and dental. In a basic way, this reflects the well-established feature of medical training in the UK, where the option to participate in overseas placements is often built into-or at least not too far removed from-clinical training programmes. ${ }^{23}$ The finding that overall, the majority of placement activity takes place during the career stages represented by student and early career supports this. So too, to a lesser extent, does the data relating to the age groups within which staff routinely fall when they work abroad: the majority of volunteers come from the age groups incorporating 'below 25' to '41-50', and almost

Table 2 Career stage while working or volunteering in another country

\begin{tabular}{|c|c|c|c|c|c|c|c|}
\hline \multirow[b]{2}{*}{ Gender } & \multicolumn{6}{|c|}{ Career stage while working or volunteering in another country } & \multirow[b]{2}{*}{ Total } \\
\hline & Preuniversity & Student & Early career & Mid-career & Experienced & Postretirement & \\
\hline \multicolumn{8}{|l|}{ Male } \\
\hline Count & 11 & 56 & 46 & 38 & 18 & 3 & 172 \\
\hline Percentage within gender & 6.4 & 32.6 & 26.7 & 22.1 & 10.5 & 1.7 & 100.0 \\
\hline \multicolumn{8}{|l|}{ Female } \\
\hline Count & 13 & 88 & 68 & 31 & 15 & 2 & 217 \\
\hline Percentage within gender & 6.0 & 40.6 & 31.3 & 14.3 & 6.9 & 0.9 & 100.0 \\
\hline \multicolumn{8}{|l|}{ Total } \\
\hline Count & 24 & 144 & 114 & 69 & 33 & 5 & 389 \\
\hline Percentage within gender & 6.2 & 37.0 & 29.3 & 17.7 & 8.5 & 1.3 & 100.0 \\
\hline
\end{tabular}


Table 3 Length of stay

\begin{tabular}{|c|c|c|c|c|c|c|}
\hline \multirow[b]{2}{*}{ Gender } & \multicolumn{5}{|c|}{ Length of time spent abroad } & \multirow[b]{2}{*}{ Total } \\
\hline & Short term & Medium term & Long term & Settlement & Other & \\
\hline \multicolumn{7}{|l|}{ Male } \\
\hline Count & 31 & 80 & 41 & 13 & 7 & 172 \\
\hline Percentage within gender & 18.0 & 46.5 & 23.8 & 7.6 & 4.1 & 100.0 \\
\hline \multicolumn{7}{|l|}{ Female } \\
\hline Count & 33 & 114 & 42 & 18 & 10 & 217 \\
\hline Percentage within gender & 15.2 & 52.5 & 19.4 & 8.3 & 4.6 & 100.0 \\
\hline \multicolumn{7}{|l|}{ Total } \\
\hline Count & 64 & 194 & 83 & 31 & 17 & 389 \\
\hline Percentage within gender & 16.5 & 49.9 & 21.3 & 8.0 & 4.4 & 100.0 \\
\hline
\end{tabular}

half of these $(49.9 \%)$ reported a medium-term placement. Medium-term placements were defined as over 2 weeks, but less than 3 months, and this time frame fits favourably with many commercially available, medically focused, placement schemes. ${ }^{16}{ }^{24}$ It is also a period which may be relatively easy to incorporate into ongoing training and employment.

It is significant in the context of the current policy initiatives aimed at greater placement facilitation ${ }^{25} 26$ that although the next most populous group in terms of placement activity were nurses, midwives and health visitors $(21.1 \%$ of volunteers), the third group: allied HCPs, was of a similar size (18.3\%). This group has not traditionally engaged in overseas placement activity as part of NHS-based training, so the relatively high percentage of staff represented here may well be primarily individuals who have self-navigated the process of organising and undertaking their overseas outing within the demands of their everyday role. The detailed makeup of such a group would be usefully analysed in further work, as they are likely to have first-hand experience of just where systemic and organisational barriers tend to develop, and will not necessarily have had the structural support enjoyed by some of the medical grades.

It can be seen that all of the multiple placement respondents came from either the medical and dental, nursing or allied HCP cadres. None of the other staff groupings were represented. This skewing of multiple placements towards the medical and dental groups may again be a reflection of the way in which medical training and career structuring within the NHS allows these cadres the freedom to engage in such activity. Conversely it may further illustrate the way in which nonclinical or lower grade staff are currently less able (or inclined) to incorporate such activity. This has serious implications in the context of providing greater access for these groups. On the one hand, there are purely systemic concerns such as incorporating time abroad into relatively constrained working practices. On the other, there is simply the issue of whether or not the

Table 4 Age group: cross tabulated against length of stay

\begin{tabular}{|c|c|c|c|c|c|c|c|c|}
\hline \multirow[b]{2}{*}{ Length of time spent abroad } & \multicolumn{7}{|c|}{ Age group (years) } & \multirow[b]{2}{*}{ Total } \\
\hline & Below 25 & $26-30$ & $31-40$ & $41-50$ & $51-60$ & $61-70$ & $71+$ & \\
\hline \multicolumn{9}{|l|}{ Short term } \\
\hline Count & 14 & 5 & 11 & 16 & 6 & 9 & 3 & 64 \\
\hline Percentage within length of time spent abroad & 21.9 & 7.8 & 17.2 & 25.0 & 9.4 & 14.1 & 4.7 & \\
\hline \multicolumn{9}{|c|}{ Medium term } \\
\hline Count & 41 & 19 & 44 & 36 & 22 & 27 & 5 & 194 \\
\hline Percentage within length of time spent abroad & 21.1 & 9.8 & 22.7 & 18.6 & 11.3 & 13.9 & 2.6 & \\
\hline \multicolumn{9}{|l|}{ Long term } \\
\hline Count & 9 & 10 & 18 & 26 & 9 & 8 & 3 & 83 \\
\hline Percentage within length of time spent abroad & 10.8 & 12.0 & 21.7 & 31.3 & 10.8 & 9.6 & 3.6 & \\
\hline \multicolumn{9}{|l|}{ Settlement } \\
\hline Count & 3 & 1 & 9 & 11 & 4 & 3 & 0 & 31 \\
\hline Percentage within length of time spent abroad & 9.7 & 3.2 & 29.0 & 35.5 & 12.9 & 9.7 & 0.0 & \\
\hline \multicolumn{9}{|l|}{ Other } \\
\hline Count & 2 & 3 & 5 & 5 & 0 & 2 & 0 & 17 \\
\hline Percentage within length of time spent abroad & 11.8 & 17.6 & 29.4 & 29.4 & 0.0 & 11.8 & 0.0 & \\
\hline \multicolumn{9}{|l|}{ Total } \\
\hline Count & 69 & 38 & 87 & 94 & 41 & 49 & 11 & 389 \\
\hline Percentage within length of time spent abroad & 17.7 & 9.8 & 22.4 & 24.2 & 10.5 & 12.6 & 2.8 & 100.0 \\
\hline
\end{tabular}


employees in these groups will see overseas training as an opportunity or an irrelevance.

\section{Conclusions and policy implications}

This survey was primarily intended to capture a snapshot of current levels of volunteering and overseas placement activity across NHS staff grades in the North West. However, as the NHS is fairly homogenous in terms of its organisational structure, relative staffing levels-and levels of volunteering and placement activity-are likely to be reproduced across the organisation as a whole. Traditionally, in the context of the NHS, it has been trainee medics who were most likely to engage with a period of work, or a placement overseas and our survey reflected this trend. The way in which electives are set up to work with established training means that such activity is relatively easy to incorporate, and is actively encouraged. The fact that a high proportion of medics reported time periods abroad during their student career stage suggest that these were either elective placements or other volunteering.

Nurses and midwives too have more recently begun to take advantage of slightly more open arrangements-in terms of access to such placements-within their career structure. In line with established NHS management and training models, our survey showed that although some degree of overseas placement activity is undertaken by a relatively high proportion of NHS staff, such activity is currently heavily skewed towards higher clinical grades. Allied HCPs and equivalent non-clinical cadres also currently report some overseas activity; however, lower grades staff are significantly underrepresented and do not generally appear to incorporate significant overseas activity-either as self-organised enterprises, or as part of ongoing training programmes. We anticipate that numbers will rise in these groups as initiatives gain momentum.

More in-depth structural analysis is required to establish how and where (within existing career paths), placement opportunities may be facilitated. The question of whether or not this will actually be a useful initiative in terms of returns to the NHS also requires further qualitative investigation.

Acknowledgements The authors would like to thank Hassan Osman for collating the data set into SPSS, and members of the MOVE project teamNatalie Tate; Eileen Cunningham; James Ackers-Johnson and Natasha Tylerfor their help in conducting the fieldwork for the survey.

Contributors JC conducted fieldwork and led on the analysis and writing. LA conceived the research idea and study design, and participated in the analysis and writing.

Disclaimer The study was funded by Health Education England (Global Health Exchange). The views expressed in this publication are those of the authors and not necessarily those of Health Education England or the Department of Health.

Funding This work was supported by a project development grant from Health Education England (Global Health Exchange). Grant ref. NURA54.
Ethics approval Approval for the study was obtained from the Ethical Research Committee, University of Salford.

Provenance and peer review Not commissioned; externally peer reviewed.

Data sharing statement The original (anonymised) data set from the survey is available on request from the authors.

Open Access This is an Open Access article distributed in accordance with the Creative Commons Attribution Non Commercial (CC BY-NC 4.0) license, which permits others to distribute, remix, adapt, build upon this work noncommercially, and license their derivative works on different terms, provided the original work is properly cited and the use is non-commercial. See: http:// creativecommons.org/licenses/by-nc/4.0/

\section{REFERENCES}

1. Reardon C, George G, Enigbokan O. The benefits of working abroad for British General Practice trainee doctors: the London deanery out of programme experience in South Africa. BMC Med Educ 2015;15:174.

2. Peate I. Nursing electives: an innovative and creative learning opportunity. Br J Nurs 2008;17:60-3.

3. Department of Health. The Framework for NHS Involvement in International Development. 2010. http://www.thet.org/healthpartnership-scheme/resources/publications-old/the-frameworkfor-nhs-involvement-in-international-development (accessed 14 Jun 2016).

4. Kumar K, Xie F. Medical students without borders: the value of undergraduate placements abroad. Med Teach 2014;36:359-60.

5. Crisp N. Turning the world upside down: the search for global health in the 21st Century. Royal Society of Medicine Press Ltd, 2010.

6. Yanagida M. Broadening your horizons. Curr Biol 1998;8:R185.

7. Crisp N. Global health partnerships: the UK contribution to health in developing countries. London: Department of Health. 2007. http:// webarchive.nationalarchives.gov.uk/20080814090248/dh.gov.uk/en/ Publicationsandstatistics/Publications/PublicationsPolicyAndGuidance/ DH_065374 (accessed 27 Jul 2016).

8. Heath S. Widening the gap: pre-university gap years and the 'economy of experience'. Br J Sociol Educ 2007;28:89-103.

9. Datt A, Dimmer K. Making an impact? A THET research report on the impact of health links on the capacity of both UK and developing countries' health institutions. [Can J Psychiat] 2011;56:1.

10. Baguley D, Killeen T, Wright J. International health links: an evaluation of partnerships between healthcare organizations in the UK and developing countries. Trop Doct 2006;36:149-54.

11. Godkin MA, Savageau JA. The effect of medical students' international experiences on attitudes toward serving underserved multicultural populations. Fam Med, 2003;35:273-8.

12. O'Donnell P, McAuliffe E, Diarmuid OD. Unchallenged good intentions: a qualitative study of the experiences of medical students on international health electives to developing countries. Hum Resour Health 2014;12:49.

13. Powel S, Bratovic E. The impact of long term youth voluntary service in Europe: a review of published and unpublished research studies. Brussels: AVSO and ProMENTE, 2006.

14. Lasker JN, Hoping to help: the promises and pitfalls of global health volunteering. Cornell University Press, 2016.

15. Shah S, Wu T. The medical student global health experience: professionalism and ethical implications. J Med Ethics 2008;34:375-8.

16. Gedde M, Edjang S, Mandeville K. Working in international Health. Oxford. Oxford University Press, 2011.

17. Fisher J. "Does it Work?"-Work for Whom? Britain and Political Conditionality since the Cold War. World Development 2015;75:13-25.

18. Harcourt W. The millennium development goals: a missed opportunity? Development 2015;48. http://www.popline.org/node/ 252380

19. Kanie $\mathrm{N}$, Abe $\mathrm{N}$, Iguchi $\mathrm{M}$, et al. Integration and diffusion in: sustainable development goals: learning from the past, looking into the future. Sustainability 2014;6:1761-75.

20. Moyo D. Dead aid. Why aid is not working and how there is another way for Africa. London: Penguin, 2009.

21. Measuring the Outcomes of Volunteering for Education (MOVE) was a study funded by Health Education England and conducted by a research team at the University of Salford (UK).

22. Electronic Staff Record Programme Data Warehouse. North West Staff in post. 2013. http://www.electronicstaffrecord.nhs.uk/esroperational/functionality/data-warehouse/ 
23. Jeffrey J, Dumont RA, Kim GY, et al. Effects of international health electives on medical student learning and career choice. Fam Med 2011;43:21-8.

24. See, for example, Knowledge for Change. http://www.knowledge4 change.org.uk/ (accessed 23 Mar 2016) or: Global Medical Projects. http://www.globalmedicalprojects.co.uk/projects (accessed 23 Mar 2016)
25. All-Party Parliamentary Group on Global Health. Improving Health at Home and Abroad: how overseas volunteering from the NHS benefits the UK and the world. A Report by the All-Party Parliamentary Group on Global Health. London. 2013.

26. All-Party Parliamentary Group on Global Health. The UK's Contribution to health globally: benefiting the country and the world. A Report by the All-Party Parliamentary Group on Global Health. London, 2015. 